\title{
Ultrastructural Identification of Ricinus communis Agglutinin-1 Positive Cells in Primary Dissociated Cell Cultures of Human Embryonic Brain*
}

\author{
Yuri BoBRYSHEV ${ }^{1}$ and Ken ASHWELL ${ }^{2}$ \\ Institute of the Human Brain ${ }^{1}$, St Petersburg, Russia; and School of Anatomy², University of New South Wales, Sydney, Australia
}

Received July 25, 1994

\begin{abstract}
Summary. While Ricinus communis agglutinin 1 (RCA-1) can be used as a specific marker to study the development and differentiation of microglial cells in human embryogenesis, little is known about the structural heterogeneity and nature of $\mathrm{RCA}-1^{+}$cells. To analyse the structural peculiarities of $\mathrm{RCA}-1^{+}$cells, we have used primary dissociated cultures of human embryonic brain. These have been used as models for investigating many of the aspects of central nervous system (CNS) HIV infection. We have shown that primary dissociated cultures from human embryos as young as 10 weeks gestation contain RCA-1 ${ }^{+}$cells. The RCA-1 $1^{+}$cells exist in two forms, those without (type I) and those with (type II) processes. The former have a poorly developed ultrastructure, while the latter have well developed ultrastructural features, such as rough endoplasmic reticulum with short cisternae, abundant ribosomes, mitochondria, lysosomes and vacuoles. Furthermore, some of these cells with processes have well developed cytoskeletal features. In this paper, the classfication of $\mathrm{RCA}-1^{+}$cells of embryonic human brain is considered and their morphology compared to microglia identified in rodent CNS.
\end{abstract}

Cell and tissue cultures of fetal nervous tissue derived from a number of species-predominantly rodentshave long been used in the study of normal development and pathology. However, reliance on studies using non-human tissues (PULliam et al., 1988; LAERIUM et al., 1990) presents problems. Many cell types in the developing human brain may behave differently from cellular homologues in rodent tissue (see below). The cultural, immunocytochemical and ultrastructural studies of scientists at the Albert Einstein College of Medicine (LyMAN et al., 1991; LEE et al., 1992),
PULLIAM et al. (1988) as well as our work (BOBRYSHEV et al., 1989; BALABANOV et al., 1992) indicate that it is possible to use human fetal tissue, derived from abortuses, to provide a laboratory model to overcome these problems (LYMAN et al., 1991). Previous welldelineated studies of dissociated glial cell cultures focused on astrocytes and oligodendroglia, whereas microglia, comprising a minor cell population, were often neglected. Since it has been shown that microglia are the major target for HIV-1 infection (DICKSON et al., 1989; KURE et al., 1989) and the specific tropism of HIV-1 for microglial cells in primary human brain cultures has been shown (WATKINS et al., 1991), the study of human fetal central nervous system (CNS) cultures with an emphasis on microglia has special signficance (HuTchins et al., 1990). More recent studies of pure microglial cultures have shown that microglia in vitro exist in two forms, ameboid and ramified, as seen in the intact brain (LEE et al., 1992).

Evidence to date indicates that compared with rodent microglia, human microglia respond differently to factors, thus emphasising the importance of studying human organotypic cultures. For example, the response of human fetal microglia to colony-stimulating factors (CSF-1) is different from rodent microglia. Mouse microglia are highly sensitive to exogenous CSF-1, resulting in marked cell proliferation (SUZUMURA et al., 1990), whereas recombinant CSF-1 or an astrocyteconditioned medium produced only marginal effects on human microglia (LEE et al., 1992). The human microglial response to lipopolysaccharide (LPS) is also quite different from that reported in neonatal rat microglia cultures. LPS promoted the differentiation

\footnotetext{
*This research was supported, in part, by a grant from the Department of Industry, Technology and Regional Development, Commonwealth of Australia.
} 
and survival of human fetal microglia (LEE et al., 1992), whereas it suppressed the proliferation of rodent microglia (GEBICKE-HAETER et al., 1989). These findings indicate that only pure human microglial, mixed or organotypic, cultures can be adequate models to study the behaviour of microglia in human nervous system disorders.

Although DEL RIO-HoRTEGA first described microglia in 1919 (DEL RIO-HORTEGA, 1919, 1932), the nature of this cell type, its origin and function remain controversial (LING and WONG, 1993; THEELE and STREIT, 1993). Few studies have investigated the development of microglia in human embryogenesis. The most extensive studies were carried out by FujIMOTO et al. (1989) and HuTCHIns et al. (1990). In the first of these works, the appearance and differentiation of microglial cells in the developing human cerebral hemispheres was investigated with the aid of nucleoside diphosphatase (NDPase) histochemistry at the light and electron microscope levels.

In the second study, the authors used the specific markers anti-macrophage antibody (EMB-11) and Ricinus communis agglutinin-1 (RCA-1) to detect microglia in intact human fetal cerebral hemispheres. HUTCHINS et al. (1990) showed that, by at least 13 weeks of gestation, microglia were detectable in the cortex. In this study it was further shown that EMB-11 labeled only ameboid microglia, while RCA-1 labeled both ameboid and the more ramified resting microglia. Those authors seggested that EMB-11 could be directed against a primitive microglial differentiation antigen, while RCA-1 labels common antigens in primitive and more mature cells (HUTCHINS et al., 1990). To date no studies have examined the ultrastructure of microglia in the very earliest stages of human brain development (prior to 13 weeks' gestation).

In the present study we have used a model of a shortlived dissociated cell culture of developing human brain to investigate the structural heterogeneity of RCA- $1^{+}$cells at the earliest stages of microglial appearance. This method has particular advantages over ultrastructural examination of intact cortical tissue in that lectin penetration is superior in cell culture. We were interested in determining firstly whether there were any $\mathrm{RCA}-1^{+}$cells present in the cortex during early development and secondly, whether there was any structural heterogeneity among these cells when they first appear and, if so, how this structural heterogeneity compares to that seen among microglia of well-studied mammals such as rodents.

\section{MATERIALS AND METHODS}

\section{Tissue collection}

Human fetal tissue was obtained from the Gynaecology Department of the 9th City Hospital, St. Petersburg, under permission of the City Health Department. Fetuses were obtained at the time of elective termination of pregnancy from normal women with no risk factors for HIV-1 infection. Material was collected in accordance with the ethical guidelines for consent contained within the Helsinki Declaration and the Medical Research Council's statement on responsibility in investigations on human subjects British Medical Council, 1964). The ages of the embryos and fetuses were determined using staging criteria (BUTLER and JUURLINK, 1987). Only tissue from 10 week gestation fetuses was used for the production of cell cultures. This age was chosen because it sees the initial appearance of the human cortical plate. Forebrains of the fetuses were immediately dissected from the head and immersed in Dulbecco's minimum essential medium (DMEM) at $4^{\circ} \mathrm{C}$, supplemented with $6 \mathrm{mg} / \mathrm{ml}$ glucose, $50 \mu \mathrm{g} / \mathrm{ml}$ gentamicin, $2.5 \mu \mathrm{g} / \mathrm{ml}$ amphotericin B.

\section{Cell culture}

The cortical tissue, free of meninges, was rinsed twice in Hank's balanced salt solution (HBSS, Gibco) containing the above antibiotic and antimycotic, cut into small pieces (approximately $1 \mathrm{~mm}$ on a side) and incubated in $\mathrm{Ca}^{2+}, \mathrm{Mg}^{2+}$-free HBSS for $30 \mathrm{~min}$. The tissue was dissociated mechanically by repeated trituration through fire-polished Pasteur pipettes followed by passage of the resulting suspension through $100 \mu \mathrm{m}$ and $40 \mu \mathrm{m}$ nylon mesh. Filtered cell suspensions were centrifuged at $500 \mathrm{~g}$ for $5 \mathrm{~min}$ and then resuspended in DMEM. Cells were plated onto poly-Llysine coated coverslips in tissue culture flasks (Petri dish, Falcon) and left undisturbed in DMEM supplemented with $15 \%$ fetal calf serum (FCS, Flow Laboratories), $2 \mathrm{mM}$ glutamine, $6 \mathrm{mg} / \mathrm{ml}$ glucose, and 40 $\mathrm{mg} / \mathrm{ml}$ gentamicin (Sigma) in a $\mathrm{CO}_{2}$-incubator at $37^{\circ} \mathrm{C}$ for 3 days.

\section{Lectin staining method}

Cell cultures were washed with phosphate buffered saline (PBS), fixed in $1 \%$ paraformaldehyde for 30 $\min$ at $4{ }^{\circ} \mathrm{C}$, then washed in PBS and incubated in $5 \%$ bovine serum albumin (BSA, Sigma) for $15 \mathrm{~min}$. The cell cultures were then incubated with biotinylated RCA-1 (Vector Laboratories), diluted 1:2000 for $2 \mathrm{~h}$ at $37^{\circ} \mathrm{C}$. Lectin binding was revealed by an avidinbiotin peroxidase complex (ABC, Vector Laboratories) 

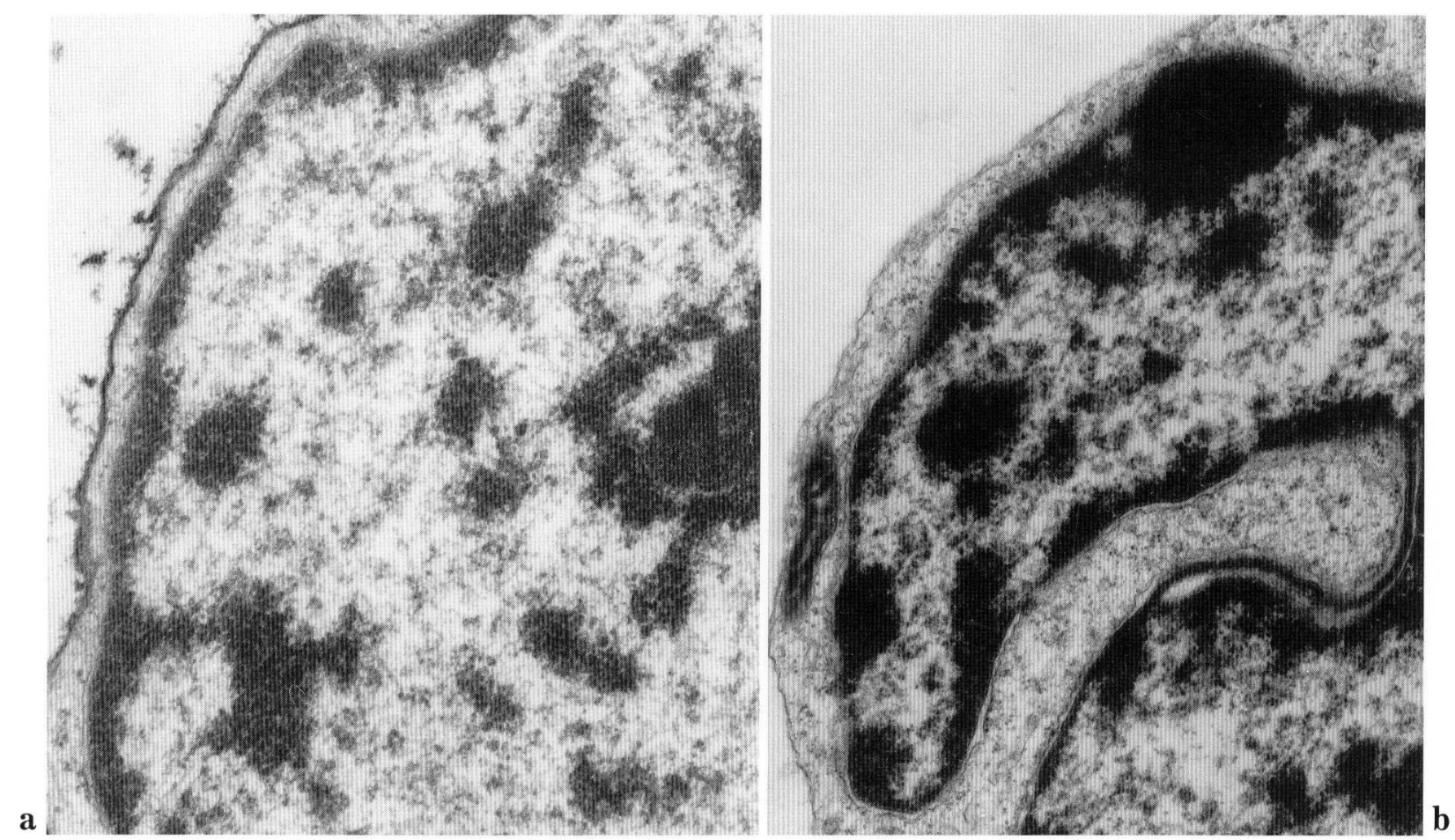

Fig. 1 a and b. RCA $-1^{+}$reaction (a) along the plasmalemma of a poorly differentiated cell $\left(\mathrm{RCA}-1^{+} / \mathrm{type} 1\right)$ as seen in a human embryonic brain culture. b. The plasmalemma of a control cell. a, b: $\times 32,000$

using 3, $3^{\prime}$-diaminobenzidine tetrachloride (DAB, Sigma) $(0.25 \mathrm{mg} / \mathrm{ml})$ as the chromogen. The specificity of the staining with RCA-1 was confirmed by preabsorbing the lectin with $1.0 \mathrm{M} \beta$-d-galactose (Sigma), which prevented staining. Controls for non-specific staining were the incubation of cell cultures with $1 \%$ BSA in the absence of lectin or the omission of the ABCcomplex from the second step. Neither of these control cultures showed labelling.

\section{Electron microscopy}

For transmission electron microscopy, the cell cultures, stained with RCA-1, were washed in PBS (5 washes of $5 \mathrm{~min}$ each) and then fixed for $30 \mathrm{~min}$ in $2.5 \%$ glutaradehyde in $\mathrm{PBS}\left(4^{\circ} \mathrm{C}\right)$ and postfixed for 1 h in $1 \% \mathrm{OsO}_{4}$ at $4^{\circ} \mathrm{C}$ in the same buffer. Cultures adhered to coverslips were embedded in Araldite as used previously (BOBRYSHEv et al., 1989). After embedding, the Araldite plug (with cells at its surface) was removed from the coverslips by immersion in liquid nitrogen. Ultrathin sections were cut perpendicular to the plane of culture, stained with uranyl acetate (30 min at room temperature) and lead citrate (45 min at room temperature) and examined with the aid of an Hitachi H7000 electron microscope at an accelerating voltage of $75 \mathrm{kV}$.

\section{RESULTS}

Three days after seeding, the dissociated cells were aggregated and formed primitive cell clusters about 1 to $2 \mathrm{~mm}$ in diameter. Isolated cells were also seen at some distance from these clusters. Both the clusters and isolated cells were seen to form abundant processes by this stage of culture. The cytochemical reaction with RCA-1 was performed at 3 days after seeding.

For the description of our results, we have felt it prudent to avoid the use of the usual terms for classifying microglia at the light microscope level (i. e., round or ameboid microglia), since such categories have boundaries which differ from one author to another and, even within a given study, boundaries between classes are often indistinct.

Electronmicroscopy in conjunction with RCA-1 cytochemistry showed that relatively few of the cells in culture demonstrated an RCA-1 positive reaction (Fig. 1a), while all of the cells of control cultures failed to show electron dense cell membranes due to the reaction product (Fig. 1b). Two distinct populations of $\mathrm{RCA}-1^{+}$cells could be recognised. The first type (RCA- $1^{+} /$type I) was relatively small in diameter (4-6 $\mu \mathrm{m})$. These poorly differentiated cells had a very 


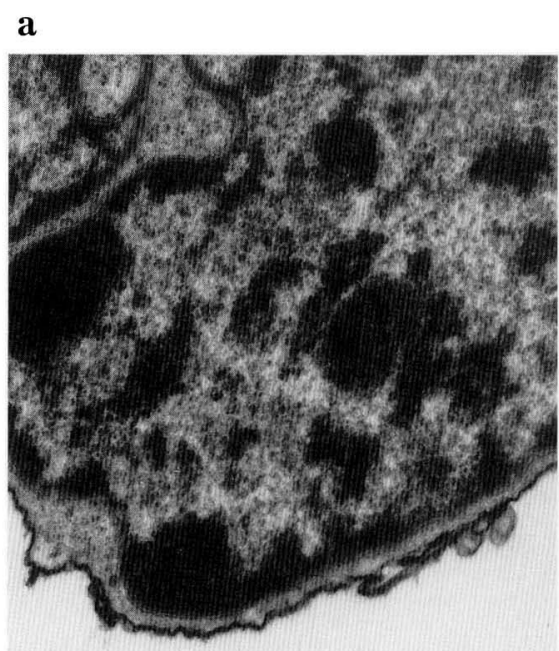

b

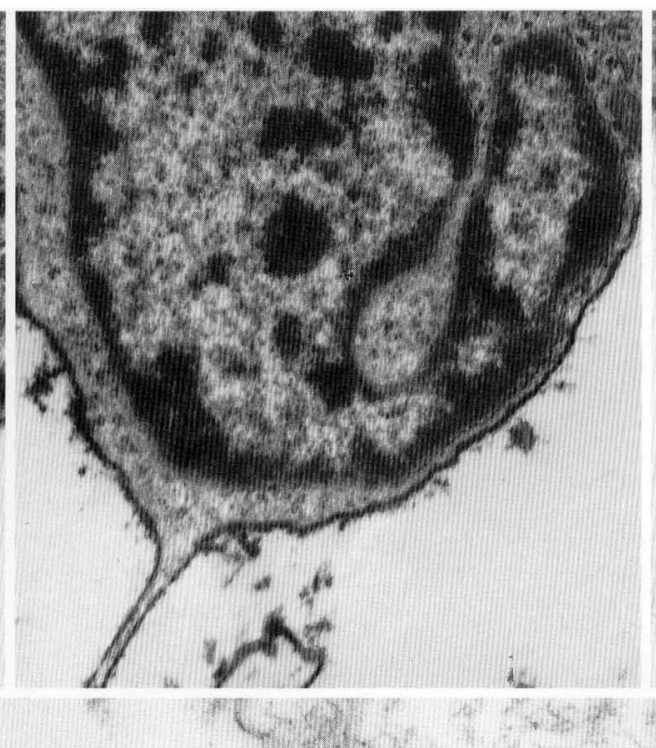

c

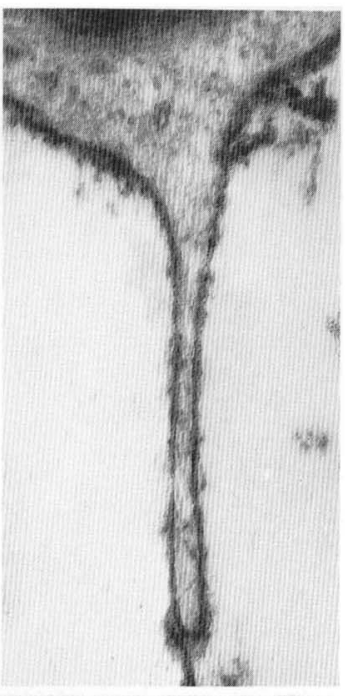

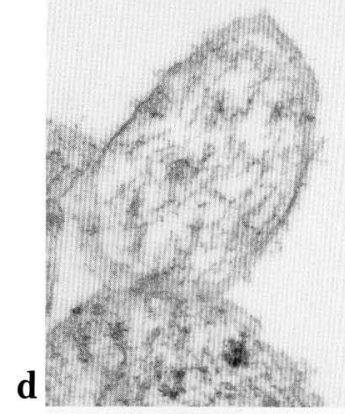
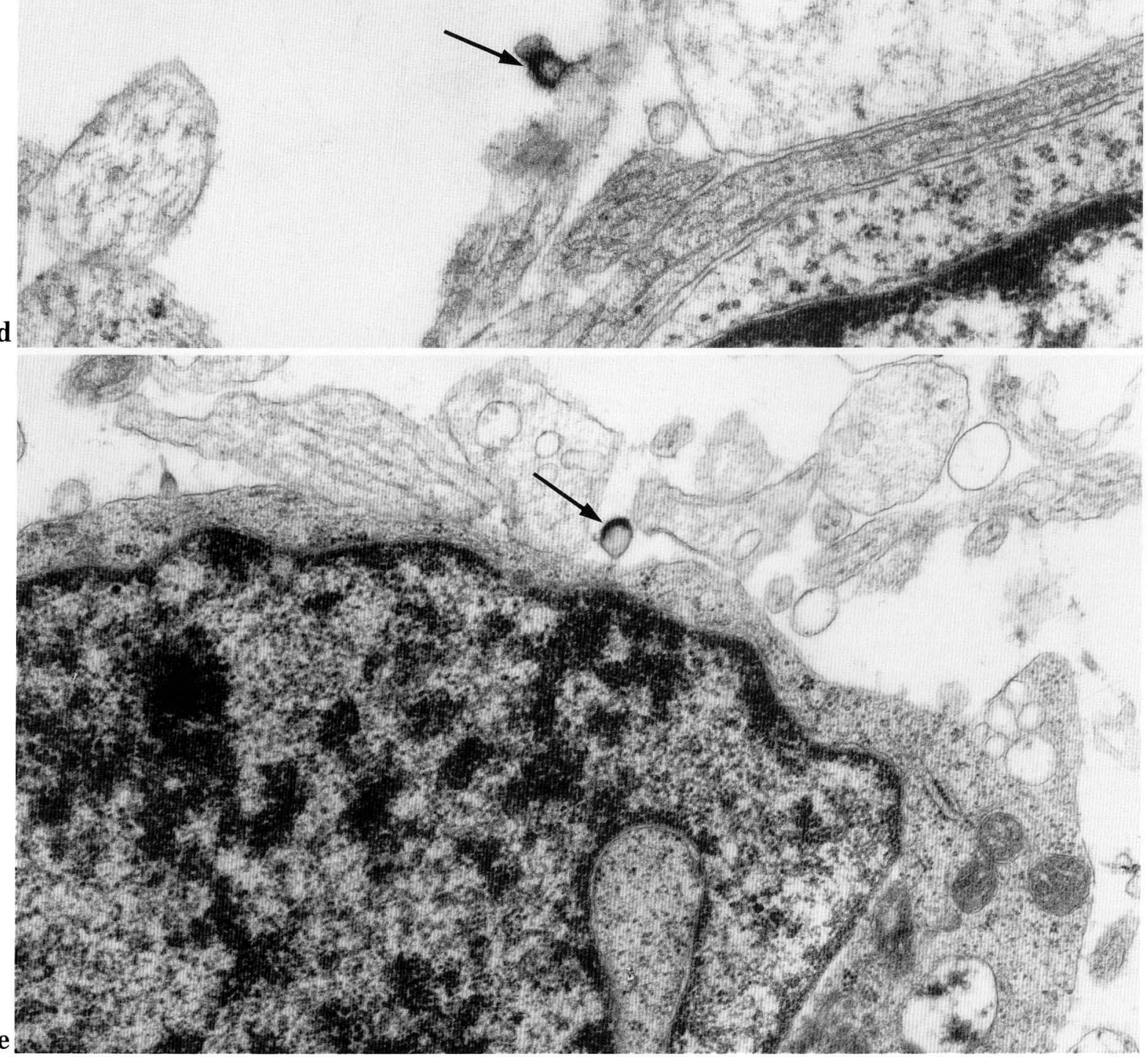

Fig. 2a-e. Legend on the opposite page. 
small volume of cytoplasm around the nucleus, and were characterised by the high activity of the histochemical reaction along all external membranes (Figs. 1a, 2a, b). These cells were located predominantly on the surface of clusters. The cytoplasm of these cells had a medium electron density with few organelles. It was possible to see on representative sections only a few separate cisternae of endoplasmic reticulum, occasional free ribosomes and mitochondria. Nuclei of these cells had an oval or bean-shaped appearance on cross-section, with strongly electrondense heterochromatin around the internal nuclear membrane. In addition, some small and large clusters of heterochromatin were located throughout the entire nucleoplasm. The majority of these cells were without processes (Fig. 2a). However, occasional cells, having the ultrastructural features described above, also exhibited fine hair-like processes (of about 100 nm diameter) (Fig. 2b, c). It was possible sometimes to see the processes of RCA- $1^{+}$cells among $\mathrm{RCA}-1^{-}$ cells on the surface of cell clusters (Fig. 2d) and within cell clusters (Fig. 2e).

A second population of $\mathrm{RCA}-1^{+}$cells could also be identified (RCA- $1^{+} /$type II). Cells of this second group appeared to be more differentiated, having well developed cytoplasm (Figs. 3, 4). The intensity (activity) of the cytochemical reaction along the cell body plasmalemma (external plasmatic membrane) was noticeably less than in cells of type I. Type II cells were also located in the surface layers of the clusters as well as deep within them, while several cells were found separately between clusters. These cells were characterized by abundant short cisternae of rough endoplasmic reticulum, many free ribosomes with some joined into polysomes, some mitochondria, lysosomes and occasional separate lipid droplets (Figs. 3, 4). Some small and large vesicles and vacuoles were also present (Figs. 3, 4). The cytoplasm was characterized by a medium electron density of the cytomatrix. Nuclei of this group were irregular in form, with heterochromatin located along all internal surfaces of the nuclear membrane as well as being dispersed in the nucleoplasm among the euchromatin. These cells often formed processes whose external membranes usually had a higher level of cytochemical RCA-1-peroxidase reaction than the cell body. The processes of these cells were readily identified on sections by their similar appearance to adjacent labelled perinuclear cytoplasm (namely the medium electron density of the cytomatrix and the presence of large vesicles or vacuoles) (Fig. 3). Sometimes it was possible to see multiple processes of $\mathrm{RCA}-1^{+}$ cells in single sections.

Electron microscopic analysis showed that the two groups of RCA- $1^{+}$cells differ in the organization of their cytoskeletons and have a very different content of filaments (Fig. 5). It was not possible to find any filaments in the cytoplasm of the poorly differentiated cells (RCA-1+/type I) using routine electron microscopy (Figs. 1a, 2a, b, 5a). By contrast, subpopulations of RCA-1 $1^{+}$type II cells showed considerable heterogeneity in their cytoskeletal apperance (Figs. 3, 4, 5b, c). There were usually a few filaments in the cytoplasm of most of these cells (subgroup RCA- $1^{+}$/type IIA) (Figs. 3, 4, 5b), but sometimes it was possible to find individual filaments or groups of such filaments, not only in the cytoplasm of the cell body, but also in the cell processes (Fig. 3b). A few microtubules could also be found in the cytoplasm of the cell body, but these were never seen in the cell processes of type IIA cells (Figs. 3, 4, 5b). Forming a second subgroup (RCA-1+/type IIB) were a few cells with high RCA-1 binding on the plasmalemma and many microtubules in both the cell body and processes (Fig. $5 c, d$ ). The processes of these cells could be readily identified by the medium electron density of the cytoplasm matrix. These cells also had filaments visible in their cytoplasm (Fig. 5c). In comparison with the previously described type IIA, the cells of type IIB were characterised by reduced amounts of cisternae of rough endoplasmic reticulum, and far fewer vesicles and vacuoles. Lipid droplets were never found in the cytoplasm of these cells.

\section{DISCUSSION}

Lectin Ricinus communis agglutinin-1 is considered a specific histochemical marker for normal human microglia (MANNOJI et al., 1986) and has been used for a study of human embryogenesis (HuTCHINS et al., 1990). However, little is known about the structural heterogeneity and nature of RCA-1 $1^{+}$cells. Little is known as well about the ultrastructural characteristics of microglial cell in human embryogenesis (Fujimoto et al., 1989); there is really only one ultrastructural description of cells in microglia-enriched cultures of the human late fetal forebrain (LEE et al., 1992). A satis-

Fig. 2 a-e. Poorly differentiated RCA-1+ cells (type 1) in a culture of human embryonic brain. Most cells lack processes (a), while occasional cells of this type have short, fine processes (b). c. Another part of the cell shown in $\mathbf{b}$. $\mathbf{d}$ and $\mathbf{e}$. The processes (arrows) of RCA- $1^{+} /$type I cells among RCA- $1^{+}$cells in culture. a, b: $\times 24,000, \mathrm{c}$ : $\times 40,000$, d, e: $\times 34,000$ 


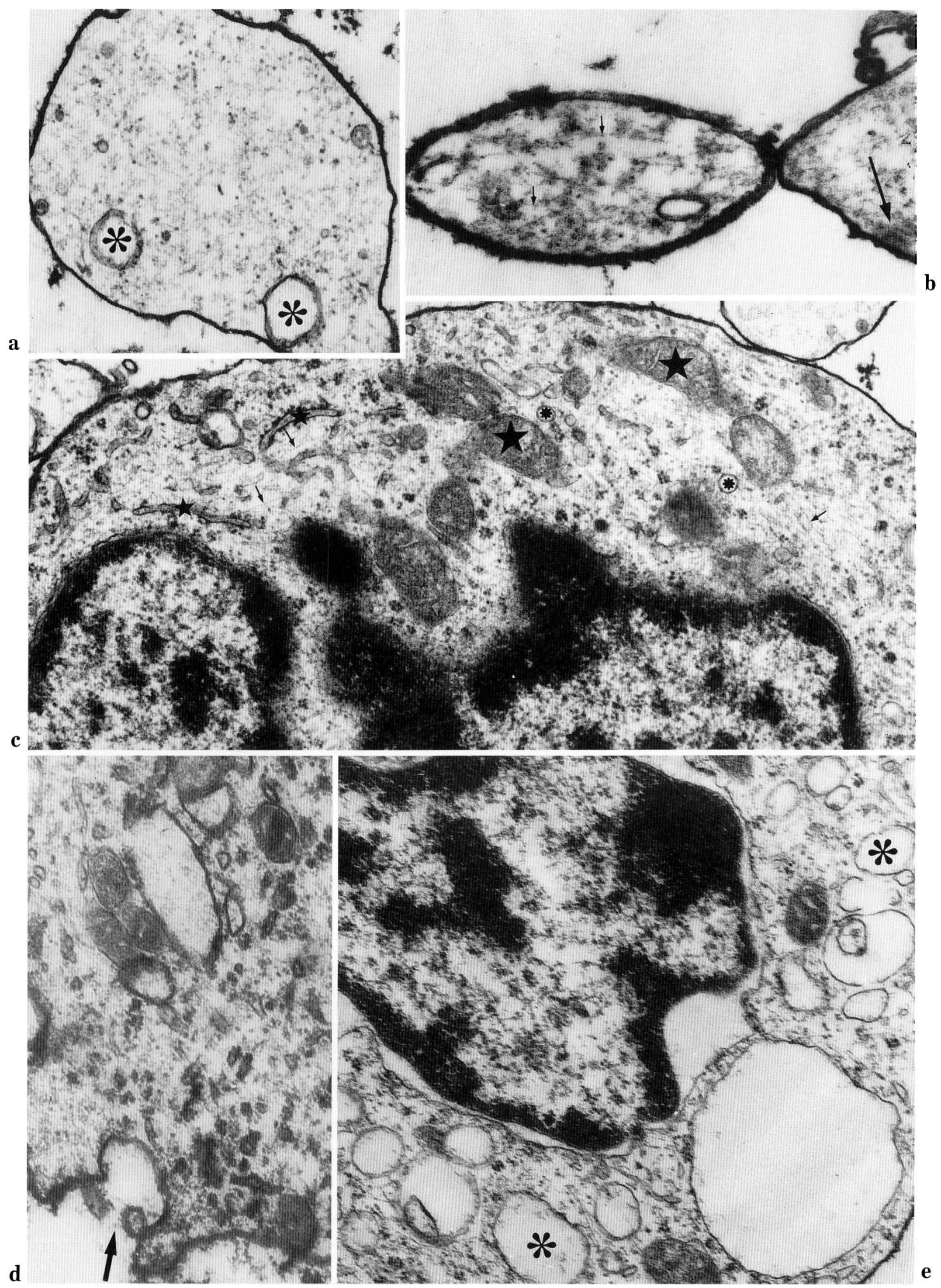

Fig. 3. Legend on the opposite page. 


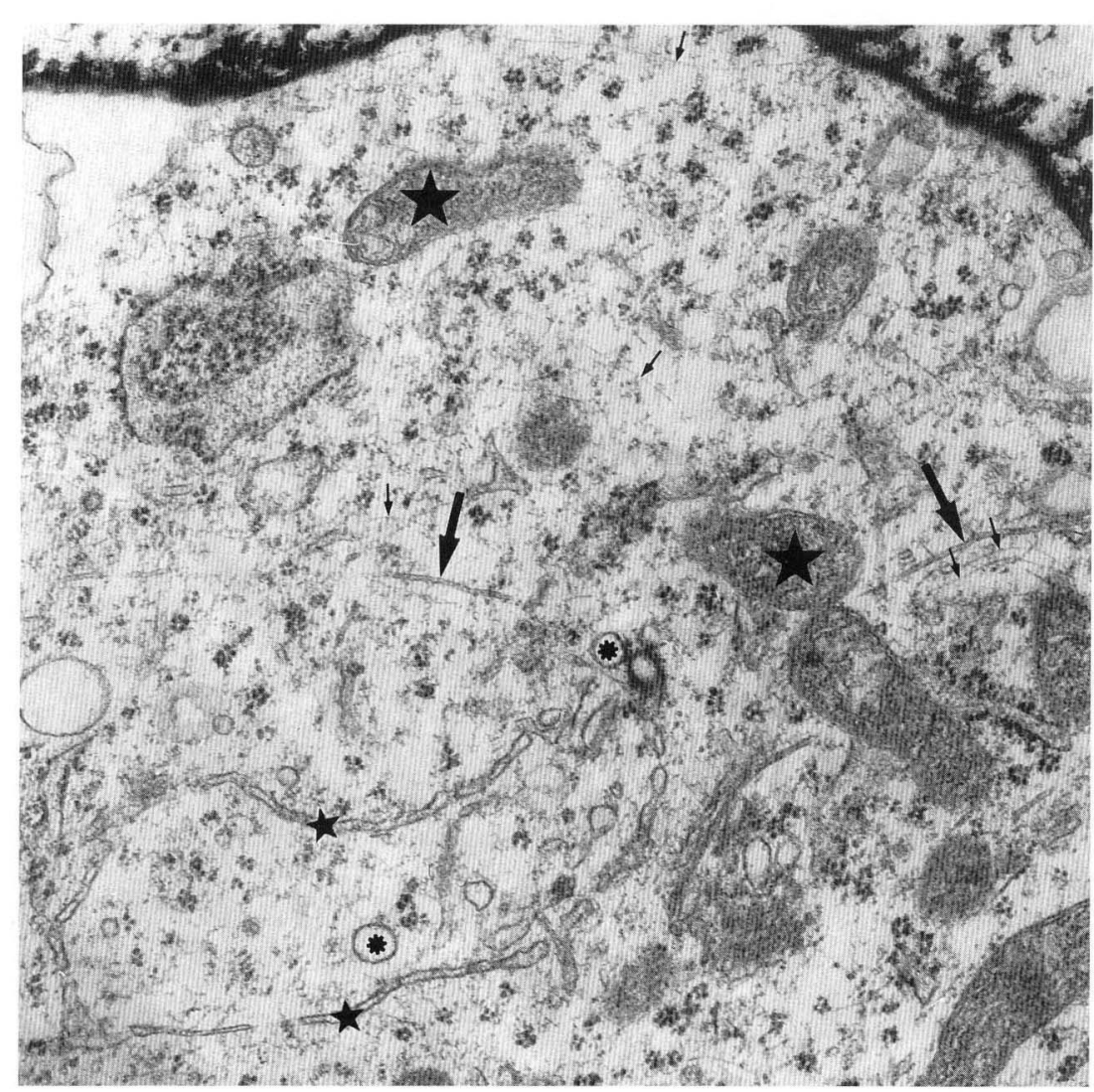

Fig. 4. Part of the cytoplasm of an RCA-1 ${ }^{+} /$type II cell. Endoplasmic reticulum ( $\star$ ), mitochondria $(\star)$, vesicles (*), filaments (small arrows) and microtubules (large arrows) are shown. $\times 50,000$

factory bridge between descriptions of cells stained by RCA-1 at the light microscope level, and cells considered as microglia by their ultrastructural features, was absent from the available literature on microglia.

Comparison of our data with descriptions of the ultrastructural characteristics of cells in microgliaenriched cultures (LEE et al., 1992) shows that the ultrastructure of $\mathrm{RCA}^{+}$/type II cells in culture is very similar to that of supposed microglial cells in primary human dissociated CNS cultures obtained from abortuses of 16 to 24 weeks gestational age (LEE et al., 1992). There are also many similarities in ultrastructural features between $\mathrm{RCA}^{+}$cells in our study and microglia identified in early fetal life in other mammals. Probably the most detailed studies of early ultrastructure in this cell type were carried out by STURROCK $(1981,1988)$ on macrophages and microglia of the fetal mouse spinal cord and neostriatum. Neostriatal and spinal cord macrophages from stages of murine development comparable to the human fetuses used in the present study (about E14) were reported to contain numerous dense bodies, large vacuoles, phagosomes, rosettes of free ribosomes and lipid droplets. Although the ultrastructure of $\mathrm{RCA}^{+}$cells was generally similar to that described by STURROCK in the mouse, we found fewer dense bodies, phagosomes and lipid droplets in $\mathrm{RCA}^{+}$cells (even in $\mathrm{RCA}^{+}$/type II) than reported by STURROCK in mice. Studies of microglia in the postnatal rodent brain and retina have found that even well differentiated microglia, such as the primitive microglial cells of the postnatal

Fig. 3. Well-differentiated RCA-1+/type II cells and their processes in culture. a and b. The cell processes contain vacuoles $(*)$, a powder-like material of medium electron density, isolated (small arrows) and clustered (large arrow) filaments. c-e. Rough endoplasmic reticulum $(\star)$, mitochondria ( $\star$ ), and vesicles (*) are also shown. The large arrow in $\mathbf{d}$ indicates invaginating plasmalemma forming an endocytotic vacuole. a, b: $\times 43,000$, c: $\times 34,000, \mathrm{~d}, \mathrm{e}: \times 28,000$ 

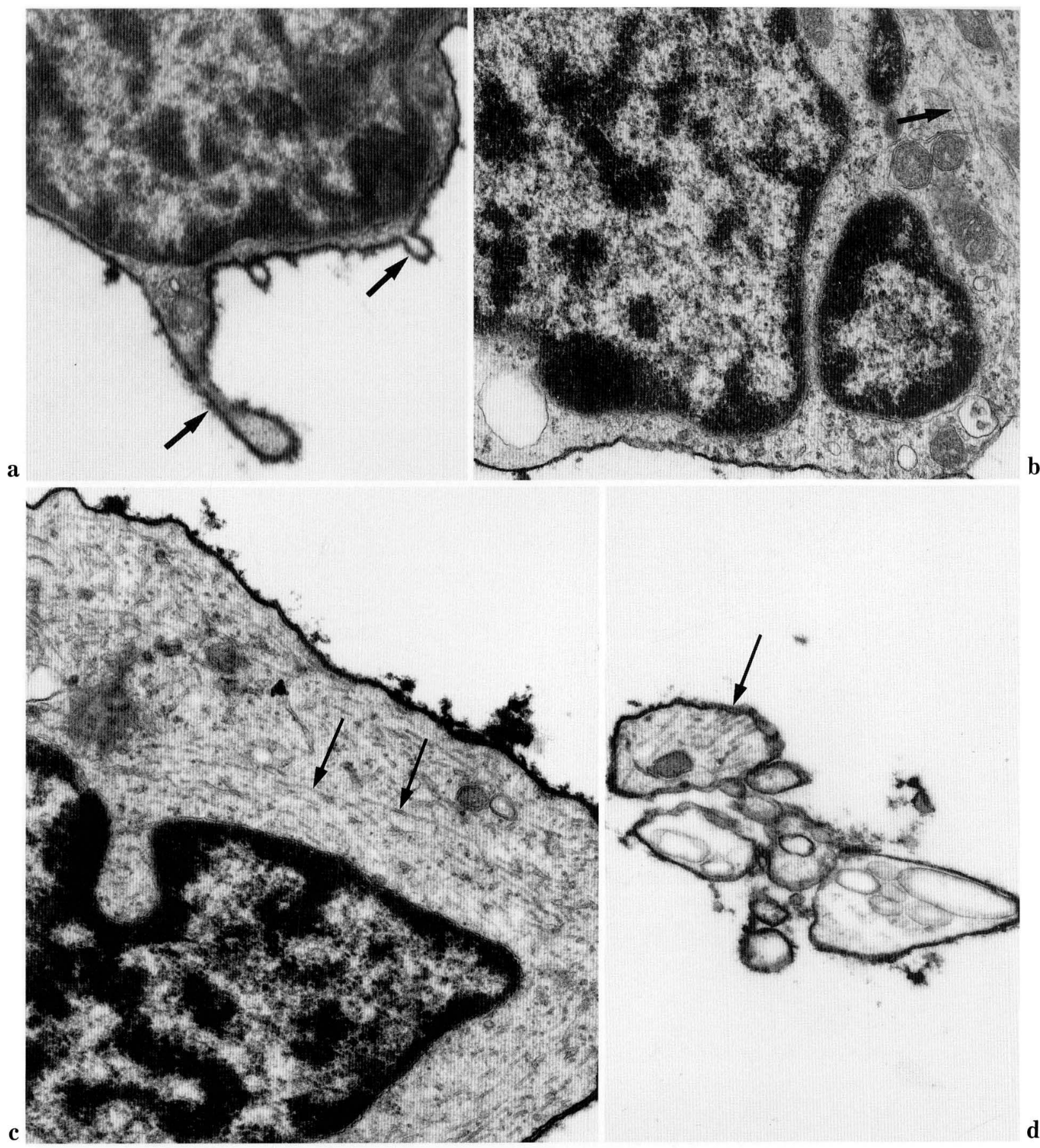

Fig. 5. Heterogeneity of RCA-1 $1^{+}$cells in culture. a. A poorly differentiated cell (type I) forming fine processes (arrows). Filaments and microtubules are not visible. b. Cell bodies of well-differentiated (type IIA) cells, with a few filaments and microtubules (arrow). c. Cell bodies of well-differentiated type IIB cells, with many microtubules (arrows). d. A group of cell processes; the process of a type IIB cell is indicated by an arrow. a: $\times 4,000, \mathrm{~b}, \mathrm{c}: \times 23,000, \mathrm{e}: \times 27,000$ 
rodent cerebral cortex (MURABE and SANO, 1982) or microglia in mature retina (TERUBAYASHI et al., 1984) have more prominent vacuolization, and more frequent dense bodies and phagosomes than we have seen with $\mathrm{RCA}^{+}$cells in human fetal CNS culture. It is uncertain at present whether these differences may be accounted for by species differences or the effects of culture.

The most extensive study to date of the microglial population in the developing human brain was carried out by HUTCHINS et al. (1990), using an anti-macrophage antibody (EMB-11) and RCA-1 as specific markers for the detection of microglia. HUTCHINS et al. (1990) showed that by at least 13 weeks of gestation, microglia were detectable in the fetal human brain. In that study, it was shown that EMB-11 labeled only ameboid microglia while RCA-1 labeled both ameboid and the more ramified resting microglia. The morphology of microglia labeled by these two reagents corresponds to that first described by DEL RIO-HORTEGA. However, in contrast to that work, HUTCHINS et al. found ameboid microglia labeled by RCA-1 and EMB-11 to be largely located within the germinal matrix where primitive neuroblasts and glioblasts arise, and not located around the blood vessels or the pial mesenchyme. Furthermore, they showed that $\mathrm{RCA}-1^{+}$cells resembling resting microglia are located exclusively within the intermediate zone and cortical plate of human fetal frontal cortex. Additionally, RCA-1 labeled cells with morphologic features intermediate between resting and ameboid microglia were located within the intermediate zone. Microglia were also found within the developing white matter tracts, with ameboid and intermediate forms of microglia particularly concentrated within the developing internal capsule.

Cerebrovascular development and differentiation begin with neural tube formation and continue throughout gestation. Therefore, even though ameboid microglia are found within the germinal zone of the frontal cerebrum of second trimester fetuses, these cells could be derived from hematogenous precursors that have entered the germinal matrix prior to the second trimester. It has frequently been reported that large numbers of monocytes infiltrate the brain parenchyma to become macrophages and ameboid microglia during the late embryonic period and the first postnatal week in rodents (LING, 1978, 1981; LING and PEnNey, 1979; LING et al., 1980; PerRy et al., 1985; PERRY and GORDON, 1988; ASHWELL, 1990, 1991). Macrophage invasion of the nervous parenchyma at these developmental stages implies extravasation from the circulating blood, as has been reported by LING (1981).

More recently, ASHWELl $(1990,1991)$ and SOROKIN et al. (1992) recognized macrophages and ameboid microglia in the developing brains of rodent embryos as early as embryonic day 11, when blood vessels have yet to develop in these regions of the CNS. However, in 3- to 5-day old chick embryos, in which CNS development is more advanced than in mouse embryos at embryonic day 11, FujIMOTO et al. (1987) were not able to detect ameboid microglia within the prosencephalon. Similarly, KAWAGUCHI (1978) reported that ameboid microglia do not appear in the roof plate of the rhombencephalon of the chick embryo until the 7th day of incubation. In contrast, MARTINPARTIDO and NAVASCUES (1990) and MARTIN-PARTIDO et al. (1991) identified macrophages of haemopoetic origin in the diencephalic floor of chick embryos as early as Hamburger and Hamilton's stage 18, and found that these cells increased noticeably in number from stage $21 \mathrm{on}$. These macrophages exhibit ultrastructural features compatible with ameboid microglia, as described by AsHwell $(1990,1991)$ and FuJIмото et al. (1987). These findings also suggest that in the chick embryo, macrophages (or ameboid microglia) begin to invade the CNS much earlier than was previously thought, at developmental stages comparable to those seen in rodents (ASHWELL, 1990, 1991).

It has been suggested that ameboid and resting microglia have different origins (Dolman, 1985; FU. JITA et al., 1981). Indeed, observations that EMB-11 and RCA-1 label different populations of microglia have been considered as support for this proposition. This could be interpreted as evidence of the different origins of the two cell types or, alternatively, EMB-11 could be directed against a primitive microglial differentiation antigen, while RCA-1 labels common antigens in primitive and more mature cells. In our study, RCA-1 labeled a structurally heterogenous cell population. The RCA-1+ cells exist in two main forms, which may be simply summarised as those with and those without cellular processes. RCA-1 $1^{+} /$type I cells (usually lacking processes) have poorly differentiated ultrastructure, while $\mathrm{RCA}-1^{+}$/type II cells (having well developed processes), are characterised by the presence in their cytoplasm of many short cisternae of rough endoplasmic reticulum, abundant ribosomes, mitochondria and vacuoles. Thus, our data are compatible with the opinion that RCA-1 can label a common antigen in both primitive and more mature microglial cells.

At the same time, however, we have found that many RCA- $1^{+} /$type II cells from the early fetal brain have a well developed cytoskeleton. Electron microscopic analysis shows that RCA-1 $1^{+}$cells differ considerably in the degree of organization of the cytoskeleton and exhibit a very different content of 
filaments. While routine electron microscopy did not allow us to find any filaments in the cytoplasm of poorly differentiated cells, many of the more differentiated (mature) $\mathrm{RCA}-1^{+}$cells of type II have filaments of intermediate type appearance in both cytoplasm and cellular processes. Some of these cells were noted to have microtubules in their cytoplasm as well. Further studies with specific antibodies are needed to investigate the cytoskeletal constituents of RCA cells.

In connection with our data, microglia and astrocytes have been shown to share antigenic determinants (DiCKSON and MATTIACE, 1989). At present the shared epitope between astrocytes and microglia is limited to one detected by a single monoclonal antibody, and therefore the ontological significance of this finding is open to dispute. It is possible that the data of HuTCHINS et al. (1990) concerning the presence of microglial cells in the germinal zone of human fetuses could be explained by at least some RCA $-1^{+}$cells being astrocytic in type.

The main problem in the study of microglial origin is likely connected with the structural heterogeneity of these cells. For this reason it is not always known what part of the "true" microglial population can be revealed by any "specific" marker for microglial cells. It is difficult to be certain of the degree of specificity of RCA-1 for different subpopulations of microglial cells. It is also possible that any anti-macrophage antibody can stain only a subset of the "true" microglial population. On the other hand, the lack of expression of many monocyte and macrophage associated antigens on microglia has long muddied the waters of the debate regarding the origin of these cells (STREIT et al., 1988; PERRY and GORDON, 1991). However, there is little room for doubt that the majority of microglia are indeed CNS tissue macrophages, although their precise lineage has not been established.

Acknowledgements. The excellent technical assistance provided in the tissue culture part of the work by Dr. I. PAVLOV and Ms. N. A. KLuEva is gratefully acknowledged.

\section{REFERENCES}

Ashwell, K.: Microglia and cell death in developing mouse cerebellum. Devel. Brain Res. 55: 219-230 (1990).

- : The distribution of microglia and cell death in the fetal rat forebrain. Devel. Brain Res. 58: 1-12 (1991).

Balabanov, Y. V., O. V. Pavlov and Y. V. Bobryshev: Preparation of pure neuronal cultures from the brains of human embryos. Cytology (Russ.) 34: 83-87 (1992).
Bobryshev, Y. V., Y. V. Balabanov, O. V. Pavlov and E. I. Chumasov: Electron microscopic study of neuron development in organotypic cultures of the human embryonic cerebral cortex. Cytology (Russ.) 31: 14531457 (1989).

British Medical Council: Human experimentation. Code of ethics of the World Medical Association and statement on responsibility in investigations on human subjects. Brit. Med. J. 2: 177-180 (1964).

Butler, H. and B. H. J. JuURLink: An atlas for staging mammalian and chick embryos. CRC Press, Baco Raton, 1987.

Del Rio-Hortega, P.: El "tercer elemento" de los centros nerviosos. I. La microglia en estado normal. II. Intervencion de la microglia en los procesos pathologicos. III. Naturaleza probable de la microglia. Bol. Soc. Esp. Biol. 9: 69-120 (1919).

: Microglia. In: (ed. by) W. PENFIELD: Cytology and cellular pathology of the nervous system, Vol. II. Paul B. Hoeber, New York, 1932 (p. 481-534).

Dickson, D. W. and L.A. Mattiace: Astrocytes and microglia in human brain share an epitope recognized by a B-lymphocyte-specific monoclonal antibody (LN1). Amer. J. Pathol. 135: 135-147 (1989).

Dickson, D. W., A. L. Belman, D. P. Young, C. Wiley, D. S. Horoupian, J. Llena, K. Kure, W. D. Lyman, R. MoRecki, S. Sitsudo and S. CHo: Central nervous system pathology in pediatric AIDS: an autopsy study. APMIS, Suppl. 8: 40-57 (1989).

Dolman, C. L.: Microglia. In: (ed. by) R. L. Davis and R. RoBERTSON: Texbook of neuropathology. Williams and Wilkins, Baltimore, 1985.

Fujimoto, E., A. Miki and H. Mızoguti: Histochemical study of the differentiation of microglial cells in the cerebral hemispheres of chick embryos and chicks. Histochemistry 87: 209-216 (1987).

- : Histochemical study of the differentiation of microglial cells in the developing human cerebral hemispheres. J. Anat. 166: 253-264 (1989).

Fujita, S., Y. Tsuchinashi and T. Kitamura: Origin, morphology and functions of the microglia. Progress Clin. Biol. Res. 59A: 141-169 (1981).

Gebicke-Haeter, P. J., J. Bauer, A. Schobert and H. NoRTHOFF: Lipopolysaccharide-free conditions in primary astrocyte cultures allow growth and isolation of microglial cells. J. Neurosci. 9: 183-194 (1989).

Hutchins, K. D., D. W. Dickson, W. K. Rashbaum and W. D. LYMAN : Localization of morphologically distinct microglial populations in the developing human fetal brain: implications for ontogeny. Devel. Brain Res. 55: 95-102 (1990).

KAWAGUCHI, M.: Electron microscopic and histochemical studies on the ameboid microglial cells in the developing chick brain. Acta Anat. Nippon. 53: 219-237 (1978).

KURE, K., W. D. Lyman, K. M. Weidenheim and D. W. DICKSON : Subacute AIDS encephalitis: identification of human immunodeficiency virus (HIV). J Neuropathol. Exp. Neurol. 48: 385 (1989). 
Laerium, O. D., S. Steinsvag and R. BJervig: Cell and tissue culture of the central nervous system: recent developments and current application. Acta Neurol. Scand. 72: 529-534 (1990).

LeE, S. C., W. LiU, C. F. Brosnan and D. W. Dickson: Characterization of primary human fetal dissociated central nervous system cultures with an emphasis on microglia. Lab. Invest. 67: 465-476 (1992).

LING, E. A.: Brain macrophages in rats following intravenous labelling of mononuclear leucocytes with colloidal carbon. J. Anat. 125: 101-106 (1978).

- : The origin and nature of microglia. In: (ed. by) S. FEDOROFF and L. HERTZ: Advances in cellular neurobiology, Vol. II. Academic Press, London, (p. 33-82).

Ling, E. A. and D. Penney: Influence of age on the entry of carbon labelled monocytes into the brain tissue of rats. Anat. Rec. 193: 604-605 (1979).

Ling, E. A. and W. C. Wong: The origin and nature of ramified and ameboid microglia: a historical review and current concepts. Glia 7: 9-18 (1993).

Ling, E. A., D, Penney and C. P. Leblond: Use of carbon labelling to demonstrate the role of blood monocytes as precursors of the ameboid cells present in the corpus callosum of postnatal rats. J. Comp. Neurol. 193: 631-657 (1980).

Lyman, W. D., M. Tricoche, W. C. Hatch, Y. KRess, F. C. ChiU and W. K. Rashbaum: Human fetal central nervous system organotypic cultures. Devel. Brain Res. 60: 155-160 (1991).

MannoJi, H., H. Yeger and L. E. Becker: A specific histochemical marker (lectin Ricinus communis agglutinin-1) for normal human microglia, and application to routine histopathology. Acta Neuropathol. 71: 341-343 (1986).

Martin-Partido, G. and J. Navascues: Macrophagelike cells in the presumptive optic pathways in the floor of the diencephalon of the chick embryo. J. Neurocytol. 19: 820-832 (1990).

Martin-Partido, G., M. A. Cuadros, C. Martin, P. Coltey and J. Navascues: Macrophage-like cells invading the suboptic necrotic centres of the avian embryo diencephalon originate from haemopoietic precursors. J. Neurocytol. 20: 962-968 (1991).

Murabe, Y. and Y. Sano: Morphological studies on neuroglia. VI. Postnatal development of microglial cells. Cell Tiss. Res. 225: 469-485 (1982).

Perry, V. H. and S. Gordon: Macrophages and microglia in the nervous system. Trends Neurosci. 11: 273277 (1988). tem. Int. Rev. Cytol. 125: 203-244 (1991).

Perry, V. H., D. A. Hume and S. Gordon: Immunocytochemical localization of macrophages and microglia in the adult and developing mouse brain. Neuroscience 15: 313-326 (1985).

Pulliam, L., M. E. Berens and M. L. Rosenblum: A normal human brain cell aggregate model for neurobiological studies. J. Neurosci. Res. 21: 521-530 (1988).

Sorokin, S. P., R. F. Hoyt, D. G. Blunt and N. A. McNeLLY: Macrophage development: II. Early ontogeny of macrophage populations in brain, liver and lungs of rat embryos as revealed by a lectin marker. Anat. Rec. 232: 527-550 (1992).

Streit, W. J., M. B. Graeber and G. W. Kreutzberg: Functional plasticity of microglia: a review. Glia 1: 301-307 (1988).

STURRock, R. R.: Microglia in the prenatal mouse striatum and spinal cord. J. Anat. 133: 499-512 (1981).

- : An ultrastructural study of the development of leptomeningeal macrophages in the mouse and rabbit. J. Anat. 156: 207-215 (1988).

Suzumura, A., M. Sawada, H. Yamamoto and T. MARUNOUCHI: Effect of colony stimulating factors on isolated microglia in vitro. J. Neuroimmunol. 30 : 111120 (1990).

Terubayashi, H., Y. Murabe, H. Fujisawa, M. Itoi and Y. IвATA: Enzymhistochemical identification of microglial cells in the rat retina: Light and electron microscopic studies. Exp. Eye Res. 39: 595-603 (1984).

Theele, D. P. and W. J. Streit: A chronicle of microglial ontogeny. Glia 7: 5-8 (1993).

W atkins, B. A., H. H. DoRn, W. B. Kelly, R. C. Armstrong, B.J. Potts, F. Michaels, C. V. Kufta and M. Dubois-DalcQ: Specific tropism of HIV-1 for microglial cells in primary human cultures. Science 249 : 549-553 (1991).
Dr. Ken ASHwELL School of Anatomy University of New South Wales Sydney, 2052, Australia 